\title{
LOS SUSTANTIVOS DE PERSONA EN -NTE. EL CASO DE LA ALTERNANCIA -NTE/-NTA PARA EL FEMENINO
}

Resumen: En cuanto a los sustantivos de persona que terminan en el sufijo -nte, llaman la atención aquellos que presentan alternancia -nte/-nta, pero que, a su vez, son comunes en cuanto al género, como, por ejemplo, presidente/presidenta al lado de el/la presidente, de manera que alternan para el femenino la terminación -nte/-nta (la presidente/la presidenta). Ahora bien, el objetivo de esta investigación consiste, por un lado, en determinar si en el Diccionario académico (2014-2019) se ha producido un incremento de sustantivos de persona en -nte comunes en cuanto al género o con alternancia de género, ya sea por incorporaciones recientes o por cambios producidos en los masculinos en -nte. Y, por otro lado, en recoger información actual sobre los femeninos en -nta que cuentan con sus correspondientes femeninos en -nte, para lo cual se han realizado consultas en el Corpus del Español del Siglo XXI (CORPES XXI). Los resultados obtenidos confirman que sí se ha producido un incremento de este grupo de voces en -nte en el Diccionario, así como que existe un mayor empleo de los sustantivos en -nta en América, respecto de España, con ciertas excepciones.

Palabras clave: género, léxico, morfología, sufijos -nte/-nta, sustantivos

Title: Nouns of Person in -nte. The Case of the Alternation -nte/-nta for the Female

\begin{abstract}
Regarding the nouns of person that end in the suffix -nte, those with alternation -nte/$n t a$ stand out, but which, in turn, are common in terms of gender, such as, for example, presidentel presidenta next to el/la presidente, so that the ending -nte/-nta (la presidente/la presidenta) alternates for the female. Now, the objective of this research consists of, on the one hand, to determine if in the Academic Dictionary (2014-2019) there has been an increase in common nouns of person in -nte, in terms of gender or with gender alternation, since either by recent incorporations or by changes produced in the male in -nte. And, on the other hand, collect current information on female in - nta who have their corresponding female in -nte, for this reason inquiries have been made in the Corpus of Spanish for the $21^{\text {st }}$ Century (CORPES XXI). The results obtained confirm that there has been an increase in this group of voices in -nte in the Dictionary, as well as, there is a greater use of nouns in - nta in America, regarding to Spain, with certain exceptions.
\end{abstract}

Keywords: gender, lexicon, morphology, suffixes -nte/-nta, nouns 


\section{INTRODUCCIÓN}

En la lengua española, dos de las cinco clases de sustantivos que establecen la relación entre el género y el sexo son los comunes en cuanto al género y los ortónimos (unisexo) ${ }^{1}$. Los sustantivos comunes en cuanto al género, que se aplican tanto al masculino como al femenino, cuentan con varios grupos diferenciados; así, por ejemplo, están los que terminan en -nte, en - $a$, en -e, en -ista, en - $o$, en - $i$ (tónica o átona) o en el sonido semivocálico representado por la grafía $-y$, en vocal tónica, en consonante (-ar, -er, -ir, -or, - ur, $-l$, $-z)$, en otras consonantes $(-f,-k,-t,-m,-g)$, los sustantivos compuestos de verbo + sustantivo, que generalmente terminan en $-s$ (o en vocal), los sustantivos que designan grados en la escala militar y los que designan por el instrumento al músico que lo toca (Ramírez 2019b: 235-236). Por su parte, los ortónimos:

Designan con exclusividad seres de uno u otro sexo. Se aplican casi exclusivamente a las personas. En ellos el rasgo 'varón' y el rasgo 'mujer' son pertinentes, necesarios [...]. Los términos unisexo inestables hacían referencia a profesiones ejercidas tradicionalmente solo por hombres o solo por mujeres. Han constituido la fuente de formación de oposiciones de desinencia variable: abogado/-a, decano/-a, rector/-a, juez/-a, árbitro/-a... y también enfermero/-a, azafato/-a. (RAE 2020: 51)

Como se puede apreciar, los sustantivos de persona en -nte se incluyen, y se estudian, dentro de los sustantivos comunes en cuanto al género. Sin embargo, cuentan con las siguientes excepciones: a) voces solo masculinas en -nte (laurente ${ }^{2}$, paginante ${ }^{3}$, levente, marzante, brigante, trinchante, oficiante, celebrante y golfante); b) voces solo masculinas en -nta (hierofanta y sicofanta); c) voces solo femeninas en -nte (parturiente y gestante); d) voces solo femeninas en -nta (parturienta y suripanta ${ }^{4}$ ) y e) voces que presentan alternancia -nte/-nta, pero que, a su vez, son comunes en cuanto al género (el presidentel la presidenta al lado de el/la presidente). Por lo tanto, los sustantivos solo masculinos y solo femeninos en -nte, con sus respectivas excepciones, se puede decir que estarían dentro del grupo de los ortónimos, pues, o bien hacen referencia a profesiones (o actividades) desempeñadas solo por hombres o solo por mujeres, o bien se refieren solo a mujeres, como es el caso de parturiente o parturienta y gestante, o se refieren solo a hombres, como es el caso de oficiante o celebrante, que aluden a 'sacerdote'. No obstante, nada impide que algunas de estas profesiones o actividades puedan ser desarrolladas hoy en día también por mujeres. Así, por ejemplo, el masculino golfante, que equivale a 'golfo (\| pillo,

\footnotetext{
Las otras tres clases de sustantivos son los epicenos, los heterónimos y los variables morfológicos (Gutiérrez 2019: 665-673).

2 Término que alude a un oficio desusado hoy en día: 'En las fábricas de papel, oficial que tenía como cometido principal acudir a las tinas con los moldes y hacer los pliegos'.

3 Término empleado en Filipinas ('obrero, cargador').

4 Es un femenino despectivo que hace alusión a una 'mujer ruin, moralmente despreciable'. Su otro sentido es desusado: 'mujer que actuaba de corista o de comparsa en el teatro'.
} 
sinvergüenza)', podría contar con el femenino golfanta, tal como ocurre con golfo/golfa. Lo mismo podría ocurrir con el masculino trinchante ('encargado de cortar la comida en la mesa'), que podría pasar a convertirse en común en cuanto al género (el/la trinchante) o en sustantivo de doble género (trinchante/trinchanta), etc.

En este estudio, además de presentar un estado de la cuestión respecto de los sustantivos de persona en -nte, se recoge una muestra de los grupos que lo conforman: 1) Los sustantivos de persona terminados en -nte que son comunes en cuanto al género; 2) Los sustantivos de persona terminados en -nte que presentan oposiciones -nte/-nta sin connotaciones particulares y 3 ) Los sustantivos de persona terminados en -nte que presentan oposiciones -nte/-nta con connotaciones particulares (asimetrías). Asimismo, dentro del segundo grupo hay dieciocho sustantivos que presentan alternancia -nte/ -nta, y que además son comunes en cuanto al género, como, por ejemplo, gerente/gerenta al lado de el/la gerente, intendente/intendenta al lado de el/la intendente, regente/regenta al lado de el/la regente, entre otros. La existencia de las variantes femeninas en -nta, por tanto, conduce a la alternancia de dos voces para aludir al femenino: una en -nta y otra en -nte, como se puede ver, por ejemplo, en la gerenta y la gerente, la intendenta y la intendente, la regenta y la regente, etc.

Así pues, esta investigación pretende determinar si en la vigesimotercera edición del Diccionario de la lengua española (2014-2019) se ha producido un incremento de sustantivos de persona en -nte comunes en cuanto al género o con alternancia de género, ya sea por incorporaciones recientes o por cambios producidos en los masculinos en -nte, así como recoger información del uso de los femeninos en -nta que cuentan con sus correspondientes femeninos en -nte. Para cumplir estos objetivos, han sido fundamentales la vigesimosegunda y la vigesimotercera edición del diccionario académico y el Corpus del Español del Siglo XXI (CORPES XXI). En consecuencia, en este trabajo se confirma, por una parte, que se ha producido un incremento de sustantivos de persona en -nte en el Diccionario de la lengua española y, por otra, que los femeninos en -nta que cuentan con sus respectivos femeninos en -nte se emplean sobre todo en América, con ciertas excepciones y matices que se presentan en el análisis de datos correspondiente.

\section{MARCO TEÓRICO}

\subsection{Definición del sufijo -nte}

En cuanto al sufijo -nte, en el Diccionario de dudas y dificultades de la lengua española se recogen dos acepciones:

(1) Sufijo de adjetivos derivados de verbos. Estos adjetivos son llamados tradicionalmente participios de presente o participios activos. El sufijo se presenta en la forma -ante cuando la base es un verbo de la conjugación en -ar; en la forma -ente o -iente, cuando la base es un verbo en -er o en -ir. Significa 'que hace la acción': amante, principiante, ambulante, conducente, equivalente [...]. Algunos de estos adjetivos se sustantivan de modo habitual; otros se han lexicalizado como nombres: presidente, asistente, 
sirviente. En algunos de estos casos se ha creado una forma femenina en - a (presidenta, etc.). (2) El sufijo - nte puede presentarse también en adjetivos no vinculados con ningún verbo español: comediante, galante, ausente, presente. (Seco 1998: 311)

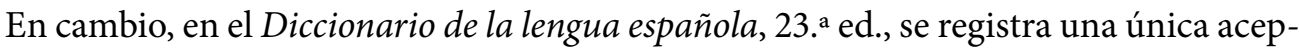
ción, que coincide con la primera que presenta Seco. Ahora bien, una diferencia entre ambas publicaciones radica en que para Seco solo "algunos de estos adjetivos se sustantivan de modo habitual; otros se han lexicalizado como nombres [...]. En algunos de estos casos se ha creado una forma femenina en - $a$ ", mientras que en el Diccionario académico - dieciséis años después- se afirma que "muchos de estos adjetivos suelen sustantivarse, $y$ algunos se han lexicalizado como sustantivos y han generado, a veces, una forma femenina en -nta" (DLE 2014, en línea). Respecto de estos términos referidos a personas, que suelen formar nombres de profesiones, ocupaciones y actividades, en ninguna de las publicaciones señaladas se hace mención de que aún haya casos solo masculinos o solo femeninos (estos son minoría), según se puede constatar en esta investigación.

\subsection{Sobre los sustantivos de persona terminados en -nte}

La Nueva gramática de la lengua española incluye un subapartado, el 6.10, denominado "Nombres de persona, instrumento y lugar (V). El sufijo -nte", en el que se afirma:

Sea cual sea su base, casi todos los nombres de persona formados con este sufijo son comunes en cuanto al género: un cantante $\sim$ una cantante; un dibujante $\sim$ una dibujante. Se exceptúan unos pocos pares, como cliente/clienta; comediante/comedianta; dependiente/dependienta; figurante/figuranta; infante/infanta; intendente/intendenta; presidente/presidenta; sirviente/sirvienta, y otros recogidos en los $\$ 2.5 \mathrm{j}$ [congregantel congreganta] y ss. y, como allí se explica, la forma en -nte de algunas de las voces citadas es común en cuanto al género. (NGLE 2009: 478)

En el capítulo 2, que trata ampliamente sobre “El género", desde el $\$ 2.5 \mathrm{j}$ hasta el $\$ 2.51$ también se mencionan diversos aspectos de las voces de persona terminadas en -nte. De cada uno de ellos, se presentan variedad de términos con alternancia -nte/-nta empleados tanto en el español de España como en el de América. Sin embargo, respecto de algunos femeninos en -nta se afirma que son voces de escaso uso, que son anticuadas, que no han pasado a los registros formales, que no se han integrado en el español general, que no se emplean en todos los países hispanohablantes y que suelen ser peyorativas (como el caso de clienta, en algunas zonas de América).

Gómez Torrego, respecto de estas voces, afirma: "En cuanto a los sustantivos acabados en -ante, -(i)ente, muchos son comunes en cuanto al género" (2007: 114, 117). A continuación, el autor menciona diversos ejemplos al respecto, entre los que se puede destacar el rechazo hacia los femeninos, que se marcan con un asterisco ${ }^{5}$. Así, por ejemplo, no

5 En cuanto a los asteriscos, conviene precisar que en lingüística se utilizan para indicar la agramaticalidad de la construcción, no obstante, se trata de un empleo que realiza Gómez Torrego. En este trabajo se 
la pacienta, no ${ }^{\otimes}$ la estudianta, no ${ }^{\otimes}$ la conferencianta, no ${ }^{\otimes}$ la participanta, no ${ }^{\otimes}$ la hablanta, no ${ }^{\otimes}$ la vivienta, no ${ }^{\otimes}$ la supervivienta, no ${ }^{\otimes}$ la viajanta, no ${ }^{\otimes}$ la naveganta, no ${ }^{\otimes}$ la ponenta, no ${ }^{\otimes}$ la escribienta, no ${ }^{\otimes}$ la gerenta, no ${ }^{\otimes}$ la farsanta, no ${ }^{\otimes}$ la militanta, no ${ }^{\otimes}$ la donanta, no ${ }^{\otimes}$ la dirigenta, no ${ }^{\otimes}$ la contendienta, no ${ }^{\otimes}$ la agenta, no ${ }^{\otimes}$ la cantanta, no ${ }^{\otimes}$ la concursanta, no ${ }^{\otimes}$ la amanta, no ${ }^{\otimes}$ la vigilanta, entre otros. Asimismo, luego añade: "Sin embargo, algunos de estos sustantivos acabados en -ante, -(i)ente presentan un femenino desinencial en - $a$ (cuando actúan como adjetivos, solo presentan la terminación en -e)". Esta afirmación la ejemplifica con un grupo de sustantivos comunes en -nte que cuentan con un femenino en -nta, y por los que no muestra ningún rechazo: figurante/figuranta al lado de una figurante, danzante/ danzanta, dependiente/dependienta al lado de la dependiente, practicante/practicanta al lado de la practicante, infante/ infanta, sirviente/sirvienta al lado de la sirviente, cliente/clienta al lado de la cliente, presidente/presidenta al lado de la presidente, comediante/comedianta al lado de la comediante, intendente/intendenta al lado de la intendente, y liante/lianta. En cuanto a los femeninos la sirviente, la cliente, la presidente y la comediante, se afirma, además, que son de empleo minoritario.

Gómez Manzano et al., en el apartado VI denominado "Aspectos gramaticales de la expresión", también se ocupan de este grupo de sustantivos de persona que terminan en -nte, en concreto cuando hacen mención de los "Sustantivos que designan profesiones desempeñadas por mujeres". Este equipo de especialistas sostiene lo siguiente: "Actualmente, está generalizada la terminación femenina para profesiones desempeñadas por mujeres y otras condiciones relativas a ellas". A continuación, incluyen cinco sustantivos de persona en femenino terminados en -nta, que son asistenta, clienta, dependienta, infanta y presidenta (2007: 622-623). Finalmente, hacen alusión a lo que afirma Seco respecto de algunos sustantivos de persona femeninos, creados a partir de sustantivos comunes en cuanto al género: "Aunque perfectamente posibles en el idioma, hay todavía cierto rechazo - por motivos sociales o culturales- ante [...] tenienta, etc." (1998: 269). Asimismo, añaden que "para reforzar la distinción de sexo, se han desarrollado formas masculinas [...], pero, sobre todo, femeninas (infanta, presidenta, dependienta, etc.) [...]. Algunos solo se emplean en femenino de forma coloquial: estudianta, concursanta" (Gómez Manzano et al. 622-623). Se puede observar que, a diferencia de Gómez Torrego, estos autores no rechazan plenamente los femeninos estudianta y concursanta, pues no llevan una marca de incorrección (bolaspa). Es más, afirman que a pesar de que son formas que se apartan del uso normativo sí se admiten en el habla informal o coloquial.

La postura de Seco, a su vez, se corresponde con la de Ambadiang, quien, cuando trata el apartado "Aspectos sociolingüísticos de la flexión de género", plantea lo siguiente:

Las soluciones formales que puede recibir la diferenciación genérica (desdoblamiento en forma masculina y femenina, moción en el artículo, adjunción de mujer, etc.) no se extienden de manera uniforme a todos los nombres de persona de estructura similar, cuyos referentes requieren la diferenciación sexual, sino que tienden a variar de un nombre a otro $y$, por tanto, pueden recibir juicios encontrados por parte de hablantes y estudiosos [...]. Las diferencias de juicio tienen que ver, más allá

han reemplazado por las bolaspas. 
de la historia de cada nombre, con las tendencias dialectales, las preferencias individuales e incluso con el nivel cultural de los hablantes. (1999: 4865)

Lliteras, por su parte, en su estudio denominado Del género derivativo al género flexivo ofrece una explicación sobre los cambios que experimentan el tratamiento y la clasificación de los sustantivos según el género. Así pues, cuando trata sobre "El encuentro de los sustantivos variables con la gramática española", la autora afirma:

Del mismo modo, las sucesivas ediciones de la Gramática de Bello van dando entrada como sustantivos variables a determinadas formas en -nte, -nta, que dos siglos antes se tomaban como invariables o, en todo caso, como adjetivos si se hacían variables. Dice Bello en el mismo capítulo dedicado a Terminación femenina de los sustantivos (1981 [1847-1860]: \$135): "Varían los [sustantivos] en ante, ente, como gigante, giganta; elefante, elefanta; pariente, parienta”. (2008: 127, 128)

Se puede decir, por tanto, que con la afirmación de Bello se empieza a mirar de manera diferente a este tipo de sustantivos de persona en -nte, que admiten ya la alternancia -nte/ -nta y, según concluye Lliteras: "Una nueva gramática comienza a desarrollarse desde mediados del siglo xix, cuando un uso "vario y caprichoso" -como decía Bello- obliga al gramático y al lexicógrafo a continuas revisiones" (2008: 147).

Gutiérrez, en su estudio, incluye un apartado denominado "Nombres de profesiones y evolución del género", en el que los sustantivos en -nte están dentro de los cinco grupos que presentan dificultades internas en la formación de femeninos (y masculinos): sustantivos en -nte, sustantivos en -ista y en - $a$, coincidencias con otra voz, sustantivos que designan individualidades y sustantivos terminados en $-e,-o,-i,-u$. Respecto de estas dificultades internas, el autor expone:

En principio, el sistema de la lengua se halla abierto a la posibilidad de componer femeninos (y masculinos) de cargo, ocupación o profesión. Son las transformaciones sociales las que crean la necesidad de diferenciar lingüísticamente el género. Sin embargo, existen factores externos e internos que pueden dificultar la formación de una desinencia doble. Se ha de advertir, no obstante, que en las manifestaciones discursivas el género común también expresa por medios formales las oposiciones de sexo a través de la concordancia (el/la estudiante moderno/a). (2019: 679)

Gutiérrez, en la cita precedente, incluye una nota al pie en la que sostiene: "Cuando una profesión era exclusivamente femenina y cambia la realidad social, la lengua presenta mayor resistencia a la creación de masculinos (azafata $\rightarrow$ azafato, enfermera $\rightarrow$ enfermero)" (679).

Por último, la Real Academia Española, en su informe, incluye un apartado titulado "Femeninos de profesión, de cargo y de dignidad", en el que también los sustantivos en -nte están dentro del grupo que presentan resistencia a la formación de femeninos: sustantivos en -nte, sustantivos en - $e$ y acortamientos. Los sustantivos en -ista y los sustantivos 
en - $a$ los enmarca dentro de los que presentan resistencia a la formación de masculinos. Sobre los sustantivos en -nte se puede leer:

Derivan en su mayoría de la desinencia invariable del participio de presente latino. No frenan la expresión del femenino a través de la concordancia (el estudiante/la estudiante, el vidente/la vidente, el conferenciante/la conferenciante...). Son esquivos a la variación de la desinencia (-nta) cuando conservan su valor adjetivo y se relacionan con una base verbal. No obstante, a lo largo de la historia se han incorporado un grupo suficiente de voces femeninas. (RAE 2020: 56)

A partir de lo expuesto por Gutiérrez y por la Real Academia Española (RAE) se puede decir que, en efecto, hoy en día se han creado muchos términos femeninos y, en algunos casos, como se podrá verificar en este estudio, se han incluido en la última edición del Diccionario de la lengua española (2014 y actualizaciones).

\subsection{La clasificación de los sustantivos de persona terminados en -nte}

\subsubsection{Los sustantivos de persona terminados en -nte que son comunes en cuanto al género}

Se presentan, a continuación, algunos ejemplos de sustantivos de persona acabados en -nte, que, de manera general, son comunes en cuanto al género, y que se registran en el $D L E$ (2014, en línea): El/la agente, el/la aspirante, el/la barbiponiente (“U. t. c. s."), el/la cantante, el/la combatiente, que en su primera acepción es voz adjetiva, 'que combate', pero tiene la marca de "Apl. a pers., u. m. c. s.", el/la conferenciante, el/la confidente, el/la contra(a)lmirante, el/la cooperante, el/la delineante, el/la dibujante, el/la dirigente ("U. t. c. s."), el/la escribiente, el/la garamante ("U. t. c. s.") -que alterna con el/la garamanta-, el/la judicante ("U. t. c. s."), el/la lugarteniente, el/la marchante ('comerciante, especialmente el que comercia con obras de arte' y 'vendedor ambulante'), el/la merchante, el/la nigromante, el/la pasante, que en su primera acepción es voz adjetiva, 'que pasa', pero tiene la marca de "Apl. a pers., u. m. c. s." (sus tres últimas acepciones referidas a persona son masculinas), el/la pirante, el/ la subintendente, el/la subteniente, el/la terrateniente, el/la viajante, que en su primera acepción es voz adjetiva, 'que viaja', y tiene la marca de "Apl. a pers., u. m. c. s., el/la vicealmirante (también se registra el femenino vicealmiranta, pero tiene el sentido de 'segunda galera de una escuadra, que montaba el segundo jefe'), el/la vidente, que en su primera acepción es adjetiva, 'que ve', y tiene la marca de "Apl. a pers., u. m. c. s." (las otras dos acepciones referidas a persona son comunes en cuanto al género) y el/la vigilante.

Como se puede apreciar, en algunos casos, el Diccionario académico recoge las marcas siguientes: "U. (usado) t. (también) c. (como) s. (sustantivo)", "Apl. (aplicado) a pers. (persona), u. (usado) t. (también) c. (como) s. (sustantivo)" y “Apl. (aplicado) a pers. (persona), u. (usado) m. (más) c. (como) s. (sustantivo)". Respecto de los adjetivos que presentan la marca "U. t. c. s., Gómez Torrego sostiene que "Cuando la RAE dice de estas palabras que «se usan también como sustantivos» (U. t. c. s.), no manifiesta el género, pero es evidente que como sustantivos son palabras comunes en cuanto al género" (2007: 115). 
Ahora bien, dentro de este grupo de sustantivos se puede decir, además, que en algunos casos se ha generado un femenino específico:

1. El/la acompañante (al lado del fem. acompañanta). El femenino acompañanta se registra en el DLE en entrada independiente con el significado de 'mujer que acompañaba a otra, generalmente como señora de compañía. Presenta la marca de "U. t. c. s.".

2. El/la almirante (al lado del fem. almiranta). El femenino almiranta se registra en entrada independiente con los sentidos de 'nave' y 'mujer del almirante', marcado este último como coloquial poco usado.

3. El/la comandante (al lado del fem. comandanta). Se registra una entrada independiente para el femenino comandanta con el sentido coloquial de 'mujer del comandante', por una parte, y el de 'nave', por otra.

4. El/la mendigante (al lado del fem. mendiganta). El femenino mendiganta se registra en entrada independiente y se marca como desusado ('mendiga'). Presenta la marca de "U. t. c. s.".

5. El/la representante (al lado del fem. representanta). El DLE recoge el femenino desusado representanta en entrada independiente con el sentido de 'actriz de teatro'.

Asimismo, constituyen "excepciones" los masculinos almirante de Castilla ('almirante que ejercía efectivamente el almirantazgo hasta que el título pasó a ser honorífico y vinculado, como ocurrió también en Aragón'), almirante de la mar, o almirante mayor de la mar (almirante $\|$ autoridad con mando absoluto sobre las armadas, navíos y galeras') y pasante de pluma ('pasante de un abogado que se encarga de escribir lo que le dicta'). Se debe agregar que algunas voces de este grupo cuentan, además de con las acepciones comunes en cuanto al género, con acepciones solo masculinas, como, por ejemplo, el agente ('persona o cosa que produce un efecto'), el pasante ('profesor, en algunas facultades, con quien van a estudiar los que están para examinarse', 'encargado de pasar o explicar la lección a alguien' y 'en algunas órdenes, religioso estudiante') y el almirante ('autoridad que en las cosas de mar tenía jurisdicción con mero mixto imperio....' 'autoridad que mandaba la armada, escuadra o flota después del capitán general' y 'caudillo, capitán, noble con autoridad o señorío; esta última acepción marcada como desusada).

\subsubsection{Los sustantivos de persona terminados en -nte que presentan oposiciones -nte/ -nta sin connotaciones particulares}

Respecto de los sustantivos de persona en -nte, en ocasiones, se presentan oposiciones -ntel -nta sin connotaciones particulares o significados añadidos. Eso sí, no todas las voces se emplean en todos los países hispanohablantes (NGLE 2009: 101). Cabe señalar también que para algunas de estas voces el Diccionario académico incluye las advertencias morfológicas siguientes: "Para el f. (femenino), u. (usada) t. (también) la forma...", "Para el f. (femenino), u. (usada) m. (más) la forma...", "Para el f. (femenino), u. (usada) solo la forma...", entre otras. Se muestran a continuación un total de veintisiete casos, que registra el DLE (2014), de los cuales solo nueve no presentan las mencionadas advertencias morfológicas:

1. El comediante/la comedianta (al lado de el/la comediante). Para el f., u. t. la forma comediante. 
2. El copresidente/la copresidenta.

3. El congregante/la congreganta.

4. El danzante/la danzanta.

5. El dependiente/la dependienta (al lado de el/la dependiente). Para el f., u. t. la forma dependiente en acep. 2.

6. El farsante/la farsanta (al lado de el/la farsante). Como sust., u. t. la forma farsante para el f. en acep. 1.

7. El figurante/la figuranta (al lado de el/la figurante). Para el f., u. t. la forma figurante en acep. 2.

8. El gerente/la gerenta (al lado de el/la gerente). Para el f., u. m. la forma gerente, excepto en Arg., Bol., Chile, Ec., Hond., Méx., Nic., Par., Perú, R. Dom., Ur. y Ven., donde se usa también gerenta.

9. El infante/la infanta (al lado de el/la infante). Para el f., u. t. la forma infante en aceps. 1 y 5; para el f., era u. t. infante en aceps. 2-4.

10. El intendente/la intendenta (al lado de el/la intendente). Para el f., u. solo la forma intendente en aceps. 1-5, excepto en Arg., Chile, Col., Ec., Méx., Nic., Par., R.Dom., Ur. y Ven., donde se usa también intendenta.

11. El marchante $2 /$ la marchanta. Tiene los sentidos de 'parroquiano' y 'vendedor al que se acude a comprar habitualmente. Se cuenta también con el/la marchante (v. 1.3.1)

12. El negociante/la negocianta (al lado de el/la negociante). Para el f., u. m. la forma negociante.

13. El practicante/la practicanta (al lado de el/la practicante). Para el f., u. t. practicante en aceps. 3 y 4.

14. El presidente/la presidenta (al lado de el/la presidente). Para el f., u. algunas veces presidente en aceps. 2 y 3.

15. El principiante/la principianta. Cuenta con la advertencia morfológica: La forma principianta, coloq., u. solo como sust. en acep. 2. Esta acepción significa: 'Que empieza a aprender o ejercer un oficio o una profesión, o a realizar una actividad. U. m. c. s.'

16. El recitantella recitanta.

17. El regente/la regenta (al lado de el/la regente). La forma regenta, solo en aceps. 4 , 9 y 10 ; en acep. 4 , u. t. regente para el $\mathrm{f}$. Aún se conservan los femeninos 'antiguamente, en algunos establecimientos de educación, profesora' y 'mujer del regente'. La segunda acepción se marca como coloquial desusada.

18. El sirviente/la sirvienta (al lado de el/la sirviente). Para el f., u. t. sirviente en acep. 2.

19. El teniente/la tenienta (al lado de el/la teniente). Para el f., u. m. teniente en aceps. 6 y 7.

Además, a los anteriores ejemplos se añaden los siguientes términos, que no designan profesión, oficio u ocupación, pero que designan persona:

20. El cliente/la clienta (al lado de el/la cliente). Para el f., u. t. la forma cliente en acep. 1; en acep. 2 ('persona que está bajo la protección o tutela de otra'), u. solo cliente.

21. El gigante/la giganta. Se registra una acepción femenina que alude a 'girasol (\| planta)'.

22. El liante/la lianta. Presenta la marca de "U. t. c. s.."

23. El pariente/la parienta (al lado de el/la pariente). Para el f., u. $\mathrm{m}$. la forma pariente en acep. 1. 
24. El penitente/la penitenta (al lado de el/la penitente). La forma penitenta, p. us., solo en acep. 4 , en la que se usa también penitente para el $\mathrm{f}$.

25. El postulante/la postulanta. En este caso, las entradas aparecen por separado. La acepción 1 presenta la marca de "U. t. c. s." En cambio, la acepción 2 sí hace referencia a un sustantivo empleado en América: 'Candidato, aspirante a un cargo'.

26. El pretendiente/la pretendienta (al lado de el/la pretendiente). Sus tres acepciones son adjetivas y presentan la marca de "U. t. c. s.. Como sust., u. t. pretendiente para el f.

27. El tunante/la tunanta (al lado de el/la tunante). Sus dos acepciones son adjetivas y presentan la marca de "U. t. c. s.". Para el f., u. t. la forma tunante.

Sin embargo, son solo masculinas las expresiones: gigante en tierra de enanos ('usado para denotar que una persona descuella no por su propio valer, sino por inferioridad de quienes la rodean'), infante de coro ('en algunas catedrales, muchacho que canta en el coro'), pariente mayor ('pariente que representa la línea primogénita o principal de un linaje'), presidente municipal ('alcalde'; término empleado en México), primer teniente ('anterior denominación del actual empleo de teniente'), segundo teniente ('anterior denominación del actual empleo de alférez'). Asimismo, algunas voces de este grupo cuentan, además de con las acepciones comunes en cuanto al género, con acepciones solo masculinas, como, por ejemplo, el dependiente ('persona que sirve a otra o es subalterna de una autoridad'), el infante ('infante de coro'), el presidente ('entre los romanos, juez gobernador de una provincia', 'en algunas religiones, sustituto del prelado' y 'maestro que, puesto en la cátedra, asistía al discípulo que realizaba un ejercicio literario'), el regente ('en las órdenes religiosas, encargado de gobernar y regir los estudios', 'en algunas antiguas escuelas y universidades, catedrático trienal', 'hombre que estaba habilitado, mediante examen, para regentar ciertas cátedras' y 'magistrado que presidía una audiencia territorial'), el sirviente ('servidor') y el escribiente ('escritor'; marcada como desusada).

Representan, por último, "excepciones" las voces o expresiones que se muestran a continuación, que o solo son femeninas, como, por ejemplo, la parturiente o la parturienta ${ }^{6}$, la bacante, la crisanta (este término se utiliza en Chile con el sentido de 'mujer que domina a su marido'. De Crisanta, personaje de una historieta), la gestante y la suripanta, o solo son masculinas, como las siguientes: el arconte, el capitulante, el celebrante, el coribante, el farfante, el fletante, el golfante, el hierofante o el hierofanta ${ }^{7}$ (excepción de masculino en -nta), el labrante, el laurente, el levente, el machacante, el maitinante, el maestrante ${ }^{8}$ el marinante, el marzante, el moderante, el mulante, el oficiante, el paginante,

$6 \quad$ En la vigesimotercera edición del $D L E$ estos términos se registran en entradas independientes y ambos son adjetivos que tienen la marca de "U. t. c. s.". El primer término, además, se marca como poco usado. En la vigesimosegunda edición del diccionario académico, en cambio, estas voces aparecían en una misma entrada: parturienta o parturiente.

7 Estas dos voces masculinas se registran en entradas independientes en la actual edición del DLE. Las acepciones figuran en la voz hierofante: 'Sacerdote de Eleusis, en Grecia, que presidía la celebración de los misterios sagrados' y 'maestro de nociones recónditas'.

8 Este sustantivo se registra en el $D L E$ actual solo como masculino: 'Cada uno de los caballeros de que se compone la maestranza'. Al respecto, en Perú, México, y otros países de América, este término se utiliza con alternancia de género (maestrante/maestranta) con el sentido de 'persona que está próxima a recibir 
el sicofante o sicofanta (excepción de masculino en -nta), el trinchante y el sobrestante de coches ('empleado que cuidaba de los coches destinados a las personas reales'). Es evidente que la parturiente o la parturienta son formas femeninas, sin embargo, también se documentan empleos de el parturiente en sentido metafórico: "El partero se vuelve parturiente cuando entendemos, al final de la novela, que el profesor escondía también un secreto" (Roche 2011: 276); " "Uf, a mí estas cosas me dan mucha pereza», responde el parturiente” (Cadena Ser, en línea); entre otros.

\subsubsection{Los sustantivos de persona terminados en -nte que presentan oposiciones -nte/-nta con connotaciones particulares}

El femenino de este tipo de sustantivos agrega en algunos casos connotaciones, $y$, a veces, hasta significados diferentes de los que corresponden al sustantivo común en cuanto al género (NGLE 2009: 102). La RAE considera que son casos de asimetrías entre masculinos y femeninos:

1. El asistente/la asistenta (al lado de el/la asistente). Existe en España el femenino asistenta para designar a la 'mujer que trabaja haciendo tareas domésticas en una casa sin residir en ella y que cobra generalmente por horas'. Además, aún permanece el femenino 'mujer del antiguo asistente (\| funcionario público)'. Presenta la advertencia morfológica "Para el f., u. m. asistente en acep. 4 ('persona que, en cualquier oficio o función, realiza labores de asistencia')".

2. El/la ayudante (al lado del fem. ayudanta). Existe, en entrada aparte, el femenino ayudanta solo con el significado de 'mujer que realiza trabajos subalternos, por lo general en oficios manuales'.

3. El/la gobernante (al lado del fem. gobernanta). Presenta la marca de "U. t. c. s.. Existe, en entrada aparte, el femenino gobernanta, pero con los significados de 'mujer que en los hoteles tiene a su cargo el servicio de un piso en lo tocante a limpieza de habitaciones, conservación de mobiliario, alfombras y demás enseres' y 'encargada de la administración de una casa o institución' (2020: 47-48).

En resumidas cuentas, después de haberse presentado estos tres primeros grupos que forman parte de las voces de persona que terminan en -nte, que generalmente son comunes en cuanto al género, se puede decir que se cuenta con las siguientes voces o expresiones femeninas en -nta, pero con alguna excepción en -nte (parturiente -que alterna con parturienta-, bacante y gestante). Se trata de voces como las siguientes: acompañanta, almiranta, comandanta, mendiganta, representanta, comedianta, copresidenta, congreganta, danzanta, dependienta, farsanta, figuranta, gerenta, infanta, intendenta, marchanta ${ }^{2}$, negocianta, practicanta, presidenta, principianta, recitanta, regenta, sirvienta, tenienta, clienta, giganta, lianta, parienta, penitenta, postulanta, pretendienta, tunanta, asistenta, ayudanta, gobernanta, cri-

el grado de maestro o magíster', significado que no incluye el Diccionario académico. Del mismo modo, en estos países americanos se documenta el empleo de doctorante/doctoranta como equivalente de doctorando/doctoranda ('persona que está próxima a recibir la borla o grado de doctor'), pero tampoco se registra en el Diccionario. 
santa y suripanta. Hay que mencionar, además, que las voces almiranta, asistenta, comandanta, intendenta, presidenta, regenta y tenienta cuentan con una acepción de 'mujer del..., que, con la excepción de asistenta ('mujer del antiguo asistente'), tienen las marcas siguientes: "f. (nombre femenino) coloq. (coloquial) p. (poco) us. (usado)", f. (nombre femenino) coloq. (coloquial)" y "f. (nombre femenino) coloq. (coloquial) desus. (desusado)".

En cuanto a los femeninos de persona en -nta, en la NGLE se afirma: "Se registran testimonios recientes de conferencianta, delineanta y otras variantes femeninas [...] que no han pasado a los registros formales ni se han integrado en el español general" (2009: 101). Se debe agregar que entre las otras variantes femeninas en -nta de las que se registran testimonios por parte de los hablantes están aspiranta, cooperanta, dibujanta, dirigenta, doctoranta, escribienta, maestranta, terratenienta, videnta $a^{9}$ y vigilanta. Respecto de estas voces femeninas en -nta, por tanto, se puede decir lo siguiente: no se registran casos en el CORPES XXI (consulta realizada el 20 de septiembre de 2020) para los femeninos aspiranta, conferencianta, cooperanta, delineanta, doctoranta, escribienta, maestranta, terratenienta, videnta y vigilanta. En cambio, sí hay registros para las voces dibujantas ( 3 casos en España en el año 2019), dirigenta(s) (3 casos en América: Chile) y terratenienta (1 caso en América: Colombia).

\section{METODOLOGÍA}

Se trata de una investigación descriptiva en la que se han empleado diversas publicaciones académicas para su elaboración, que se pueden consultar en el apartado destinado a las fuentes bibliográficas. Ahora bien, para determinar los cambios e incorporaciones de este grupo de sustantivos en -nte en la edición actual del Diccionario académico, se han realizado consultas en la vigesimosegunda edición del Diccionario de la lengua española (DRAE 2001, en línea), así como en la vigesimotercera edición del Diccionario de la lengua española (DLE 2014, en línea), con sus respectivas versiones electrónicas: 23.1 (2017), 23.2 (2018) y 23.3 (2019). Por su parte, para recoger información actual sobre los femeninos en -nta que cuentan con sus correspondientes femeninos en -nte, se ha recurrido al Corpus del Español del Siglo XXI (CORPES XXI). Las consultas en esta base de datos fueron realizadas por última vez del 10 al 15 de septiembre de 2020. En cuanto a la referenciación bibliográfica de los ejemplos seleccionados en cada uno de los dieciocho femeninos en -nta, se ha mantenido el estilo de citación empleado en el CORPES XXI.

Por un lado, el corpus que permite determinar que se han producido cambios en este tipo de sustantivos en -nte, que recoge la vigesimotercera edición del Diccionario de la lengua española (2014-2019), consta de cincuenta y siete voces. De ellas, siete son acepciones que han pasado de ser solo masculinas a comunes en cuanto al género, diez son sustantivos o expresiones en -nte que han pasado de ser masculinos a comunes en cuanto al género,

\footnotetext{
$9 \quad$ En la NGLE se recoge lo siguiente: "[S]i bien es de uso general vidente como común, existe videnta en el área andina, y se ha documentado ocasionalmente en España" (2009: 101). Sin embargo, el femenino videnta no se registra ni en el Diccionario panhispánico de dudas (DPD 2005, en línea) ni en el Diccionario de la lengua española (DLE 2014, en línea). El CORPES XXI tampoco cuenta con registros del femenino videnta.
} 
nueve son sustantivos, expresiones o acepciones en -nte (masculinos o comunes en cuanto al género) que han pasado a tener alternancia de género, veintinueve son nuevas incorporaciones de voces comunes en cuanto al género en -nte y dos son nuevas voces comunes en cuanto al género en -nte (una incorporación de acepción para cooperante y una incorporación de marca morfológica para vidente, en su acepción adjetiva). Por otro lado, el corpus de femeninos en -nta que cuentan con sus correspondientes femeninos en -nte consta de dieciocho voces, que se tratan en el apartado 1.3.2, denominado "Los sustantivos de persona terminados en -nte que presentan oposiciones -nte/-nta sin connotaciones particulares".

\section{ANÁLISIS DE LOS SUSTANTIVOS DE PERSONA QUE TERMINAN EN EL SUFIJO -NTE}

\subsection{Los sustantivos de persona terminados en -nte que presentan cambios en la vigesimotercera edición del DLE (2014)}

\subsubsection{Los sustantivos de persona terminados en -nte que han pasado de ser solo mas- culinos a comunes en cuanto al género}

En este apartado se presentan los términos -también acepciones- o expresiones referidos a persona terminados en -nte que han pasado de ser solo masculinos (en la 22. ${ }^{\text {a ed. }}$ $\operatorname{del} D R A E)$ a ser comunes en cuanto al género en la vigesimotercera edición del $D L E(2014$, en línea). Estos términos, en el diccionario vigente, se marcan como ("m. y f."), a diferencia de la 22. a ed. (2001, en línea), que los marcaba como ("com."). Por una parte, se muestran las voces en las que se han producido cambios en sus acepciones. Por otra, se presentan los términos o expresiones de persona en -nte que han pasado de ser masculinos a comunes en cuanto al género (v. Cuadros 1 y 2).

Cuadro 1 Acepciones de persona en -nte que cambian de masculinas a comunes en cuanto al género en el DLE (2014)

\begin{tabular}{|c|c|}
\hline $\begin{array}{l}\text { Sustantivos } \\
\text { en -nte }\end{array}$ & Acepciones que cambian de masculinas a comunes en el $D L E$ (2014) \\
\hline El/la agente & En su acepción 3 referida a persona. \\
\hline El/la cambiante & En su acepción 3 referida a persona. \\
\hline El/la cortante & En su acepción 2 referida a persona. \\
\hline El/la merchante & En su acepción 2 referida a persona. \\
\hline El/la regante & En los sentidos 2 y 3 que hacen alusión a persona. \\
\hline El/la sobrestante & En su acepción 2 referida a persona. \\
\hline El/la volante & $\begin{array}{l}\text { La acepción } 16 \text {-hoy } 4 \text { - cambia a común en cuanto al género ('en el fútbol, } \\
\text { jugador que se mueve en el medio campo'). Sin embargo, las acepciones } 12 \\
\text { y } 17 \text { (hoy } 13 \text { y } 17 \text { ) aún se conservan como masculinas: 'criado de librea que iba } \\
\text { a pie delante del coche o caballo de su amo...' y 'persona que tiene habilidad } \\
\text { para conducir automóviles'; esta última acepción se emplea en Argentina. } \\
\text { Existe también la voz volanta, pero no alude a persona ('volante' y 'vehículo'). }\end{array}$ \\
\hline
\end{tabular}


Cuadro 2 Sustantivos o expresiones en -nte que cambian de masculinos a comunes en cuanto al género en el DLE (2014)

\begin{tabular}{|c|c|c|}
\hline $\begin{array}{l}\text { Sustantivos o expresiones } \\
\text { en -nte }\end{array}$ & 22. a ed. $D R A E(2014)$ & 23. a ed. $D L E(2014)$ \\
\hline El/la cabildante & masculino & común en cuanto al género \\
\hline $\mathrm{El} /$ la lugarteniente & masculino & común en cuanto al género \\
\hline El/la agente comercial & masculino & común en cuanto al género \\
\hline $\begin{array}{l}\text { El/la agente de bolsa (de cambio, } \\
\text { o de cambio y bolsa) }\end{array}$ & masculino & común en cuanto al género \\
\hline El/la agente doble & masculino & común en cuanto al género \\
\hline $\mathrm{El} /$ la agente secreta & masculino & común en cuanto al género \\
\hline $\mathrm{El} /$ la agente viajera & masculino & común en cuanto al género \\
\hline El/la coagente & masculino & Apl. a pers., u. t. c. s. \\
\hline El/la promitente & masculino & U.t. c. s. \\
\hline El/la vigilante jurado & masculino & común en cuanto al género \\
\hline
\end{tabular}

\subsubsection{Los sustantivos de persona terminados en -nte masculinos o comunes en cuanto al género que han pasado a tener alternancia de género}

Se presentan los términos, expresiones y acepciones en -nte que han pasado de ser solo masculinos o comunes en cuanto al género a tener alternancia de género en la actual edición del Diccionario académico (2014):

Cuadro 3 Sustantivos, expresiones y acepciones en -nte que han pasado a tener alternancia de género en el DLE (2014)

\begin{tabular}{|c|c|c|c|}
\hline $\begin{array}{c}\text { Sustantivos } \\
\text { o expresiones en -nte }\end{array}$ & Acepciones en -nte & $\begin{array}{c}22 .^{\mathrm{a}} \text { ed. } D R A E \\
(2014)\end{array}$ & $23 .^{\text {a }}$ ed. $D R A E(2014)$ \\
\hline Bergante/berganta & & masculino & -nte/-nta \\
\hline $\begin{array}{l}\text { Dependiente/ } \\
\text { dependienta }\end{array}$ & acepción 2 & masculina & $\begin{array}{c}\text {-nte/-nta } \\
\text { Incorpora advertencia } \\
\text { morfológica: "Para } \\
\text { el f., u. t. dependiente } \\
\text { en acep. } 2 \text { " }\end{array}$ \\
\hline Farsante/farsanta & acepción desusada 2 & masculina & $\begin{array}{l}\text {-nte/-nta } \\
\text { Incorpora advertencia } \\
\text { morfológica: "Como } \\
\text { sust., u. t. farsante para } \\
\text { el f. en acep. 1" }\end{array}$ \\
\hline Gigante/giganta & acepciones $3,4,5$ y 6 & masculinas & -nte/-nta \\
\hline Infante/infanta & acepción 5 & masculina & $\begin{array}{l}\text {-nte/-nta } \\
\text { Incorpora advertencia } \\
\text { morfológica: "Para el f., } \\
\text { u. t. infante en aceps. } 1 \\
\text { y 5; para el f., era u. t. } \\
\text { infante en aceps. } 2-4 \text { " }\end{array}$ \\
\hline
\end{tabular}




\begin{tabular}{|c|c|c|c|}
\hline $\begin{array}{c}\text { Sustantivos } \\
\text { o expresiones en }-n t e\end{array}$ & Acepciones en -nte & $\begin{array}{c}\text { 22. a ed. DRAE } \\
(2014)\end{array}$ & $23 .^{a}$ ed. $D R A E(2014)$ \\
\hline Intendente/intendenta & acepciones $2,3,4$ y 5 & masculinas & $\begin{array}{c}\text {-nte/-nta } \\
\text { Amplía la advertencia } \\
\text { morfológica: "Para } \\
\text { el f., u. solo la forma } \\
\text { intendente en aceps. } \\
\text { 1-5, excepto en Arg., } \\
\text { Chile, Col., Ec., Méx., } \\
\text { Nic., Par., R. Dom., Ur. } \\
\text { y Ven., donde se usa t. } \\
\text { intendenta" }\end{array}$ \\
\hline $\begin{array}{l}\text { Intendente municipal/ } \\
\text { intendenta municipal }\end{array}$ & & masculina & -nte/-nta \\
\hline Presidente/presidenta & $\begin{array}{c}\text { acepciones } 2 \text { y } 3 \\
(\text { antes } 2,3,4)\end{array}$ & $\begin{array}{c}\text { comunes en cuanto } \\
\text { al género }\end{array}$ & $\begin{array}{c}\text {-nte/-nta } \\
\text { Incorpora advertencia } \\
\text { morfológica: "Para } \\
\text { el f., u. algunas veces } \\
\text { presidente en aceps. } 2 \\
\text { y 3" }\end{array}$ \\
\hline Regente/regenta & acepción 4 (antes 3) & masculina & $\begin{array}{l}\text {-nte/-nta } \\
\text { Incorpora advertencia } \\
\text { morfológica: "La forma } \\
\text { regenta, solo en aceps. } \\
4,9 \text { y } 10 \text {; en acep. } 4 \text {, u. t. } \\
\text { regente para el f." }\end{array}$ \\
\hline
\end{tabular}

\subsection{Las nuevas voces de persona comunes en cuanto al género terminadas en -nte que registra la vigesimotercera edición del DLE (2014)}

Se presentan también algunas de las nuevas voces de persona terminadas en el sufijo -nte que registra la vigesimotercera edición del diccionario académico, un total de veintinueve, que en su mayor parte son adjetivas, pero presentan las marcas de "U. t. c. s." y "Apl. a pers., u. t. c. s." En cambio, sí son sustantivos: agente (de seguros), alimentante, quiromante y sufragante:

1. El acreditante/la acreditante (U. t. c. s.).

2. El adorante/la adorante (U. t. c. s.).

3. El agente de seguros/la agente de seguros (m. y f.).

4. El agraviante/la agraviante (Apl. a pers., u. t. c. s.).

5. El alegante/la alegante (U. t. c. s.).

6. El alimentante/la alimentante (m. y f.).

7. El añorante/la añorante (Apl. a pers., u. t. c. s.).

8. El asediante/la asediante (Apl. a pers., u. t. c. s.).

9. El colaborante/la colaborante (U. t. c. s.).

10. El concedente/la concedente (Apl. a pers., u. t. c. s.). 
11. El cortejante/la cortejante (U. t. c. s.).

12. El estetizante/la estetizante (Apl. a pers., u. t. c. s.).

13. El extranjerizante/la extranjerizante (Apl. a pers., u. t. c. s.).

14. El filosofante/la filosofante (Apl. a pers., u. t. c. s.).

15. El farmacodependiente/la farmacodependiente (U. t. c. s.).

16. El implorante/la implorante (Apl. a pers., u. t. c. s.).

17. El interviniente/la interviniente (Apl. a pers., u. t. c. s.).

18. El interpelante/la interpelante (U. t. c. s.).

19. El licitante/la licitante (U. t. c. s.).

20. El migrante/la migrante (Apl. a pers., u. t. c. s.).

21. El monologantella monologante (Apl. a pers., u. t. c. s.).

22. El optante/la optante (Apl. a pers., u. t. c. s.).

23. El pactante/la pactante (Apl. a pers., u. t. c. s.).

24. El pagante/la pagante (Apl. a pers., u. t. c. s.).

25. El preguntante/la preguntante (Apl. a pers., u. t. c. s.).

26. El querulante/la querulante (U. t. c. s.).

27. El quiromante/la quiromante (m. y f.).

28. El repitentella repitente (U. t. c. s.). En la 22.a ed. del diccionario académico se registra la voz repitiente (en la actual también), pero tiene otros sentidos.

29. El sufragante/la sufragante (m. y f.).

También es necesario mencionar voces como el/la cooperante, que incorpora la acepción 2 referida a persona y el/la vidente, que en su acepción adjetiva 1, incorpora la marca "Apl. a pers., u. t. c. s.".

\subsection{Datos relativos a los sustantivos femeninos de persona en -nta que cuentan con sus correspondientes sustantivos en -nte}

Se han realizado consultas de los dieciocho femeninos en -nta que se recogen en el apartado 1.3.2, voces que, por un lado, cuentan con su correspondiente sustantivo en -nte, es decir, alternan para el femenino la voz terminada en -nta y la terminada en -nte, y, por otro, presentan la marca morfológica: "Para el f. (femenino), u. (usada) t. (también) la forma...", "Para el f. (femenino), u. (usada) m. (más) la forma...", "Para el f. (femenino), u. (usada) solo la forma...", etc. Los trece primeros sustantivos pertenecen al grupo de los que designan profesión, oficio u ocupación: comedianta, dependienta, farsanta, figuranta, gerenta, infanta, intendenta, negocianta, practicanta, presidenta, regenta, sirvienta y tenienta. Los cinco siguientes, por su parte, solo designan persona: clienta, parienta, penitenta, pretendienta y tunanta. Por consiguiente, al consultar en el CORPES XXI, del que se han seleccionado ejemplos en contexto, se han obtenido los siguientes resultados: 
Cuadro 4 Resultados de las consultas realizadas en el CORPES XXI de los sustantivos femeninos de persona en -nta que alternan con sus correspondientes sustantivos en -nte

\begin{tabular}{|c|c|c|c|} 
Voces consultadas & Casos registrados & Documentos & Casos/Lugares \\
\hline Comedianta & 7 & 6 & $\begin{array}{c}6 \text { en España y 1 } \\
\text { en América }\end{array}$ \\
\hline
\end{tabular}

Ejemplo: Yo también me he convertido en una comedianta [...]. (Eyre, Pilar: Mi color favorito es verte. España: Planeta, 2014).

\begin{tabular}{l|l|l|c} 
Dependienta & 131 & 101 & $\begin{array}{c}98 \text { en España y 33 } \\
\text { en América }\end{array}$
\end{tabular}

Ejemplo: Había conseguido acabar sus estudios de Administración de Empresas mientras trabajaba de DEPEndienta ocasional. (Conde-Lobato, Miguel: Los lobos no piden perdón. Barcelona: Penguin Random House Grupo Editorial, 2019).

\begin{tabular}{l|c|c|c} 
Farsanta & No hay registros & No hay registros & $\begin{array}{c}\text { No hay registros } \\
1 \text { en América } \\
\text { Figuranta }\end{array}$ \\
1 & 1 & (Venezuela)
\end{tabular}

Ejemplo: La ministra Hanson es fiel Figuranta de la farsa revolucionaria [...]. (Bahachille M., Miguel: "El albañil de la ministro Hanson". El Universal. Caracas: eluniversal.com, 2012-03-26).

\begin{tabular}{l|l|l|l} 
Gerenta & 128 & 106 & 128 en América
\end{tabular}

Ejemplo: La Gerenta senior de Deloitte, Florencia Carriquiry dijo que la información publicada este jueves confirma el diagnóstico de estancamiento. (Comesaña, Federico; Mondautti, Masimiliano: "Economía estancada y con menor proyección de crecimiento para 2019”. El Observador. Montevideo: elobservador.com.uy, 2019-03-29).

\begin{tabular}{|c|c|c|c|}
\hline Infanta & 1190 & 421 & $\begin{array}{c}657 \text { en España, } \\
530 \text { en América, } 2 \\
\text { en Guinea Ecuatorial } \\
\text { y } 1 \text { sin identificar }\end{array}$ \\
\hline
\end{tabular}

Ejemplo: Asistieron el rey emérito don Juan Carlos y LA Infanta Elena. (Lorca, Antonio: “Las Ventas, ridiculizada”. El País. http://elpais.com: elpais.com, 2019-06-05).
Intendenta
257
160
257 en América

Ejemplo: La diputada nacional del Chaco por Cambiemos, Aída Ayala, quien fuera InTENDEnta de la ciudad de Resistencia [...]. (Fernández de Kirchner, Cristina: Sinceramente. Buenos Aires: Sudamericana, 2019).
Negocianta 1 1 1 en América (Honduras)

Ejemplo: El balcón es bien bonito, concluyó su descripción de NEgocianta [...]. (Carías, Marcos: El ángel de la bola de oro. Honduras: Iberoamericana, 2009).

\begin{tabular}{l|c|c|c} 
Practicanta & No hay registros & No hay registros & No hay registros \\
& & & 1305 en España, \\
& & 4764 en América, \\
Presidenta & 6088 & 4183 & $\begin{array}{c}5 \text { en Guinea Ecuatorial, } \\
\text { en Filipinas y 13 sin } \\
\text { identificar }\end{array}$
\end{tabular}

Ejemplo: La reunión de la comisión de Legislación General se inició con la designación como nueva PRESIDENTA de la correntina Ana Almirón [...]. ("El oficialismo consiguió dictamen de mayoría para la Ley de Góndolas”. El Economista. Buenos Aires: eleconomista.com.ar, 2020-02-18). 


\begin{tabular}{|c|c|c|c|}
\hline Voces consultadas & Casos registrados & Documentos & Casos/Lugares \\
\hline Regenta & 159 & 84 & $\begin{array}{c}120 \text { en España, } 37 \\
\text { en América, } 1 \\
\text { en Guinea Ecuatorial } \\
\text { y } 1 \text { sin identificar }\end{array}$ \\
\hline
\end{tabular}

Ejemplo: [...] [L]a riña se quedó en amago gracias a las artes pacificadoras de LA REGENTA del local [...]. (Benítez Reyes, Felipe: El azar y viceversa. Barcelona: Planeta, 2016).

\begin{tabular}{c|c|c|c} 
Sirvienta & 971 & 476 & $\begin{array}{c}164 \text { en España, 806 } \\
\text { en América y 1 } \\
\text { en Filipinas }\end{array}$
\end{tabular}

Ejemplo: Si no teníamos una SIRviEnTA, teníamos dos. (Guerriero, Leila: Opus Gelber: Retrato de un pianista. Barcelona: Anagrama, 2019).

\begin{tabular}{l|l|l|l} 
Tenienta & 5 & 5 & 5 en España
\end{tabular} Ejemplo: No quiero que el pueblo sepa que LA TENIENTA es una borracha. (Muñoz, José Luis: Cazadores en la nieve. Barcelona: Ediciones Versátil, 2016).

\begin{tabular}{l|l|l|l} 
Clienta & 591 & 334 & $\begin{array}{c}311 \text { en España y 280 } \\
\text { en América }\end{array}$
\end{tabular}

Ejemplo: Hace varios años que soy CLIENTA de Granel Madrid, una de esas tiendas de productos al peso que se han puesto de moda. (Gosálvez, Patricia: “"En serio, trae papel. Urge»". El País. Madrid: elpais.com, 2019-06-06).

\begin{tabular}{l|l|l|l} 
Parienta & 159 & 92 & $\begin{array}{c}58 \text { en España, 97 } \\
\text { en América y 4 } \\
\text { en Guinea Ecuatorial }\end{array}$
\end{tabular}

Ejemplo: Ana, totalmente alucinada, no sabe a qué frente dedicar su atención, la verdad: Pepe Guil y LA PARIENTA, a tortas [...]. (Tristante, Jerónimo: Secretos. Sevilla: Algaida, 2019).

\begin{tabular}{l|c|c|c} 
Penitenta & No hay registros & No hay registros & No hay registros \\
Pretendienta & 3 & 3 & 3 en España
\end{tabular}

Ejemplo: Así que más te vale aprovechar esta oportunidad, que si no le voy a buscar otra PRETENDIENTA mejor. (Sánchez Arévalo, Daniel: La isla de Alice. Barcelona: Planeta, 2015).

Tunanta 5 4 2 en España y 3 en América

Ejemplo: Tienes mala pinta, me dijo mi superencargado, qué habrás hecho este fin de semana, TUNANTA, para estar así de hecha polvo. (Mestre, Javier: Komatsu PC-340. Madrid: Caballo de Troya, 2011).

En cuanto a los femeninos en -nta, según los datos obtenidos del CORPES XXI, se puede afirmar, en primer lugar, que los femeninos que presentan un mayor número de registros son presidenta (6088), infanta (1190), sirvienta (971) y clienta (591), con una diferencia notable de casos registrados para presidenta respecto del resto de voces estudiadas. En segundo lugar, el CORPES XXI no registra casos para farsanta, practicanta y penitenta. En tercer lugar, los femeninos que cuentan con más registros en España son presidenta (1305), infanta (657), clienta (311) y sirvienta (164). En cuarto lugar, el CORPES XXI no registra casos en España para las voces farsanta, figuranta, gerenta, intendenta, negocianta, practicanta y penitenta. En quinto lugar, los femeninos que cuentan con más 
registros en América son presidenta (4764), sirvienta (806), infanta (530) y clienta (280). Por último, el CORPES XXI no registra casos para farsanta, practicanta, tenienta, penitenta y pretendienta (v. Gráficos 1, 2 y 3).

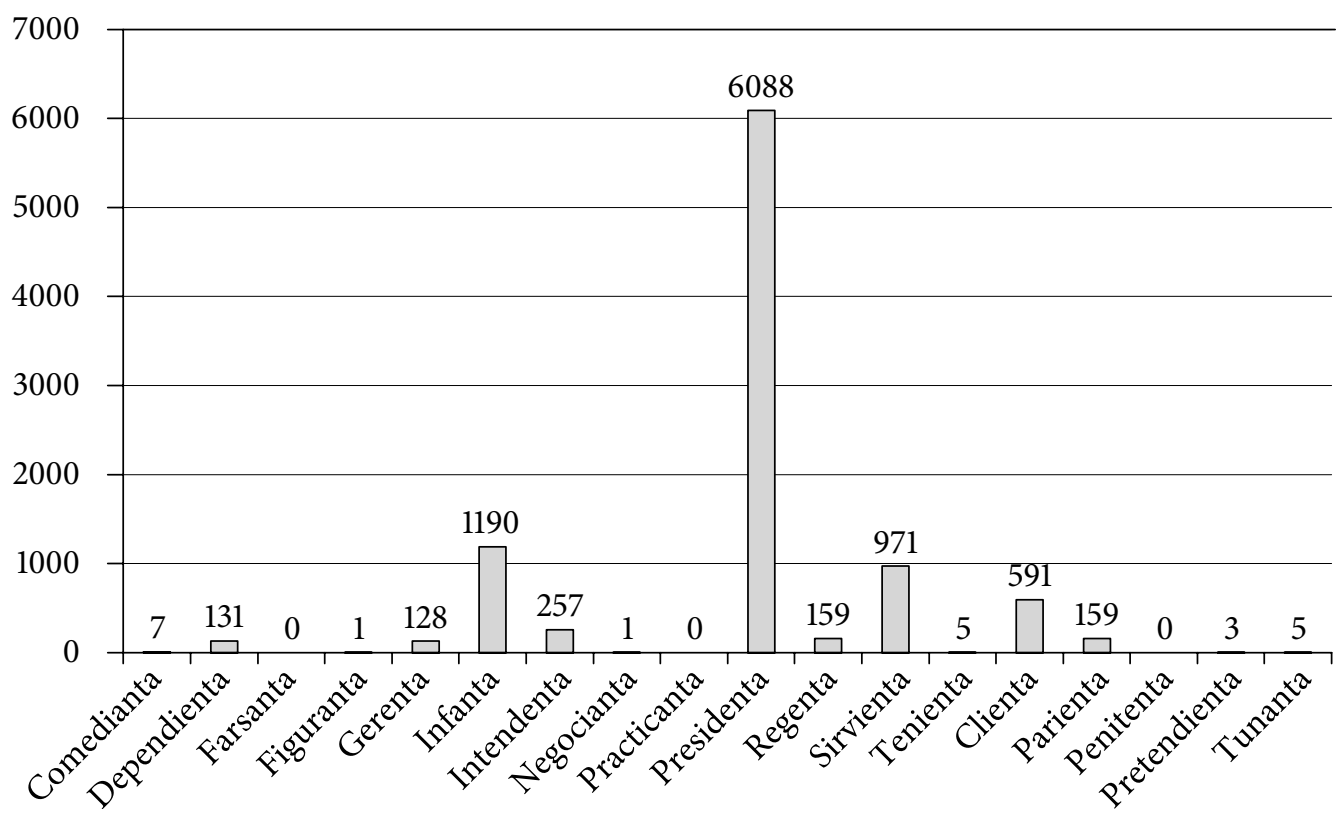

Gráfico 1 Total de femeninos en -nta: España y América (CORPES XXI)

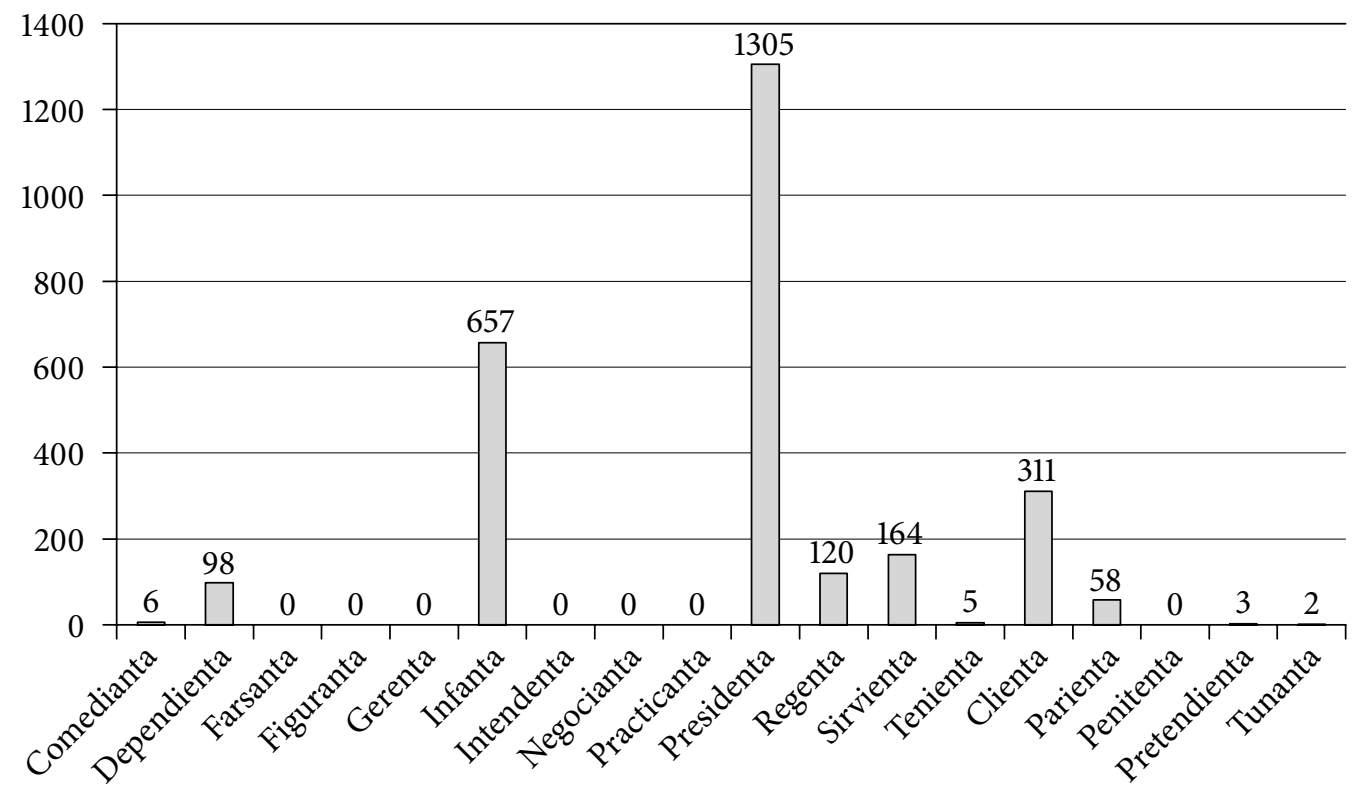

Gráfico 2 Femeninos en -nta en España (CORPES XXI) 


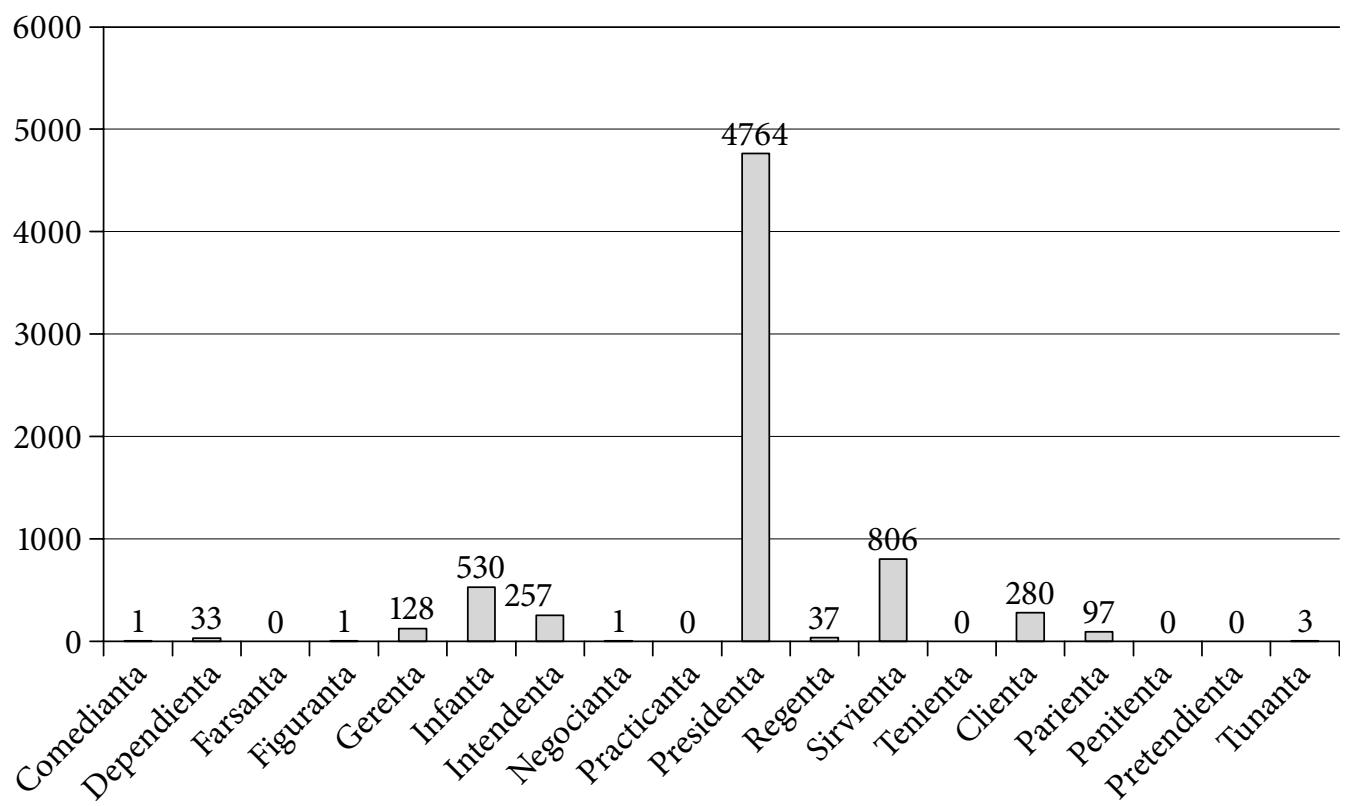

Gráfico 3 Femeninos en -nta en América (CORPES XXI)

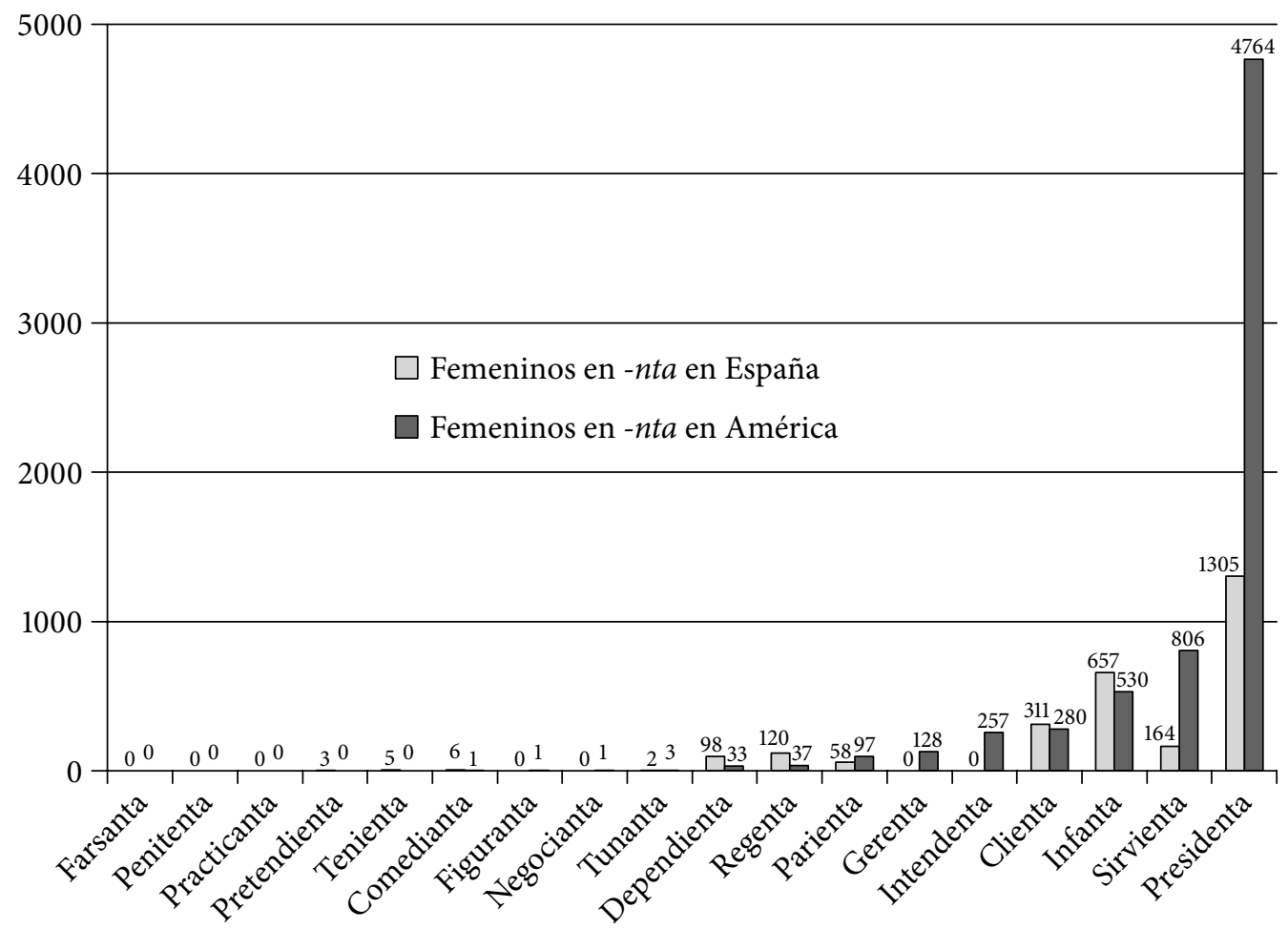

Gráfico 4 Comparación de los femeninos en -nta en España y América (CORPES XXI) 
En resumidas cuentas, según se puede apreciar en el Gráfico 4, los femeninos en -nta que registran más casos en América en el CORPES XXI son presidenta (4764 frente a los 1305 de España), sirvienta (806 frente a 164), intendenta (257 frente a 0), gerenta (128 frente a 0), parienta (97 frente a 58), tunanta ( 3 frente a 2$)$, figuranta ( 1 frente a 0 ) y negocianta (1 frente a 0 ). Por su parte, los femeninos en -nta que registran más casos en España en el CORPES XXI son infanta (657 frente a los 530 de América), clienta (311 frente a 280), regenta (120 frente a 37), dependienta (98 frente a 33), comedianta ( 6 frente a 1$)$, tenienta ( 5 frente a 0 ) y pretendienta ( 3 frente a 0$)$.

\section{CONCLUSIONES}

La realización de este estudio permite afirmar, en primer lugar, que el conjunto de los sustantivos de persona que terminan en el sufijo -nte se clasifica en tres grupos: los que son comunes en cuanto al género -con algunas excepciones-, los que presentan oposiciones -ntel-nta sin connotaciones particulares o significados añadidos y los que presentan oposiciones -nte/-nta con connotaciones o significados diferentes en el femenino (asimetrías). En segundo lugar, se ha podido constatar que, por un lado, hay un grupo de voces y acepciones que han pasado de ser consideradas solo masculinas a ser comunes en cuanto al género en el Diccionario académico, como es el caso de el/la cabildante o el/la lugarteniente y, por otro, un grupo de voces y acepciones que han pasado de ser masculinas o comunes en cuanto al género a tener alternancia de género, como, por ejemplo, el bergante/la berganta; cuestión que ya era considerada por los hablantes, es decir, el cambio no ha sido de uso, sino de marca lexicográfica. Por último, esta publicación académica también recoge nuevas incorporaciones en -nte, que en su mayor parte son voces adjetivas, pero que tienen la marca de "U. t. c. s." y "Apl. a pers., u. t. c. s.", salvo los términos alimentante, quiromante, sufragante y agente (de seguros), que sí se marcan como sustantivos.

Asimismo, respecto del grupo de los sustantivos que son comunes en cuanto al género, se puede decir que hay algunos casos que presentan un femenino específico como, por ejemplo, el/la acompañante al lado de la acompañanta, el/la almirante al lado de la almiranta y el/la comandante al lado de la comandanta; sin embargo, el femenino hace referencia a una ocupación realizada en épocas pasadas ('mujer que acompañaba...'), a un "femenino coloquial" y a un "femenino coloquial poco usado", respectivamente. Luego, sobre los sustantivos que presentan oposiciones -nte/-nta sin connotaciones particulares o significados añadidos, se puede destacar que el Diccionario académico incluye diversas advertencias morfológicas en algunas voces: "Para el f. (femenino), u. (usada) t. (también) la forma..."; "Para el f. (femenino), u. (usada) m. (más) la forma..."; "Para el f. (femenino), u. (usada) solo la forma..., entre otras, lo que origina casos como los siguientes: presidente/presidenta al lado de el/la presidente o intendente/intendenta al lado de el/ la intendente, de modo que alternan para el femenino la terminación -ntel-nta (la presidente/la presidenta y la intendente/la intendenta). Además, del grupo de los que presentan oposiciones -nte/-nta con connotaciones o significados diferentes en el femenino, se puede comprobar que es minoritario. 
Ahora bien, respecto de los sustantivos femeninos en -nta que cuentan con sus respectivos femeninos en -nte, se puede afirmar que, del total de la muestra consultada -dieciocho voces-, ocho cuentan con más registros en América que en España (presidenta, sirvienta, intendenta, gerenta, parienta, tunanta, figuranta y negocianta), cinco no cuentan con registros (farsanta, practicanta, tenienta, penitenta y pretendienta) y las otras cinco cuentan con menos registros respecto de España (infanta, clienta, regenta, dependienta y comedianta). Por su parte, seis sustantivos femeninos en -nta cuentan con más registros en España respecto de América (infanta, clienta, regenta, dependienta, comedianta y pretendienta), siete no cuentan con registros en España (farsanta, figuranta, gerenta, intendenta, negocianta, practicanta y penitenta) y cinco cuentan con menos registros en España (presidenta, sirvienta, parienta, tenienta y tunanta). También es necesario mencionar que farsanta, practicanta y penitenta no cuentan con registros en el CORPES XXI ni en América ni en España.

Por consiguiente, se puede ratificar que los sustantivos de persona en -nta se emplean sobre todo en América, pero predomina, con una diferencia numérica destacable, el uso de la forma común en -nte. Sin embargo, el Diccionario registra estas voces tanto con alternancia de género como con advertencia morfológica, por lo que en muchos casos se podrían producir titubeos por parte de los hablantes de español al decantarse por el femenino en -nta o por el femenino en -nte, elección en la que intervienen diversos factores sociolingüísticos, que habría que determinar en una futura investigación. De igual manera, los hablantes tienen la libertad de crear femeninos en -nta en todos los sustantivos comunes en cuanto al género en -nte, como, por ejemplo, conferencianta, cooperanta, dirigenta, monologanta, quiromanta, sufraganta, terratenienta, videnta, vigilanta, etc., que luego se podrían incorporar en el Diccionario académico, pues, como afirma la RAE:

[A] unque ciertas terminaciones constituyen un freno a la formación de femeninos desinenciales, la lengua mantiene siempre abierta la puerta. La creación de este tipo de femeninos suele causar sorpresa y rechazo. Con el paso del tiempo, si encajan en el sistema de la lengua, terminan por normalizarse. (2020:56)

\section{BIBLIOGRAFÍA}

Ambadiang, Théophile (1999) “La flexión nominal. Género y número". En: Ignacio Bosque y Violeta Demonte (eds.) Gramática descriptiva de la lengua española, vol. 3. Madrid, Espasa: 4843-4913.

Bello, Andrés (1981 [1847-1860]) Gramática de la lengua castellana destinada al uso de los americanos. Ed. Ramón Trujillo. España, Cabildo Insular de Tenerife.

Gómez, Pilar, Cuesta, Paloma, García-Page, Mario y Estévez, Ángeles (2007) Ejercicios de gramática y de expresión. (Con nociones teóricas). 2. ${ }^{2}$ ed. Madrid, Editorial Centro de Estudios Ramón Areces, S. A. 
GómEz, Leonardo (2007) Hablar y escribir correctamente. Gramática normativa del español actual. Madrid, Arco/Libros.

GutiÉrREZ, Salvador (2019) “Género, sexo y formación de femeninos". Moenia. 25: 655-685.

Lliteras, Margarita (2008) "Del género derivativo al género flexivo". En: Marina A. Maqueira y María Dolores Martínez (eds.) Gramma-temas 3. España y Portugal en la tradición gramatical. León, Universidad de León: 125-148.

Ramírez García, Jessica (2014) Las profesiones en femenino. Madrid, Editorial Bubok.

---- (2019a) "El género de los sustantivos de persona terminados en -ista". En: Marco Martos y Marco Antonio Lovón (eds.) Léxico y Literatura: Homenaje a Andrés Bello. Lima, Academia Peruana de la Lengua: 315-325.

----- (2019b) "Los sustantivos de personas que designan profesiones y que hacen siempre el femenino en - $a$ ”. Nasledje. 42: 235-252.

Real Academia Española y Asociación de Academias de la Lengua Española (2009) Nueva gramática de la lengua española, 3 vols. Madrid, Espasa.

Real Academia Española (2020) "Informe de la Real Academia Española sobre el uso del lenguaje inclusivo en la Constitución española, elaborado a petición de la vicepresidenta de Gobierno". Boletín de Información Lingüística de la Real Academia Española. 14: 1-242.

Roche, Myriam (2011) "Caminos de la introspección en algunas novelas de la duda existencial: un peso en el mundo y esta pared de hielo, de José María Guelbenzu”. En: Geneviève Champeau, Jean-François Carcelén, Georges Tyras y Fernando Valls (eds.) Nuevos derroteros de la narrativa española actual. España, Prensas de la Universidad de Zaragoza: 275-287.

Seco, Manuel (1998) Diccionario de dudas y dificultades de la lengua española. Madrid, Espasa.

\section{SITOGRAFÍA}

Patiño, José María (periodista). “Otra paradoja se perfila en la Moncloa porque Mariano Rajoy puede conseguir una crisis de gobierno sin cambios..." [episodio de podcast]. En: Acuerdos y desacuerdos. Cadena Ser de España. https://cadenaser.com/ programa/2015/06/18/hoy_por_hoy/1434607047_813357.html [18.06.2015].

Real Academia Española y Asociación de Academias de la Lengua Española (2001) [DRAE] Diccionario de la lengua española 22. ${ }^{a}$ ed. https://www.rae.es/recursos/diccionarios/diccionarios-anteriores-1726-2001/diccionario-de-la-lengua-espanola-2001 [29.05.2019].

---- (2005) [DPD] Diccionario panhispánico de dudas. https://www.rae.es/dpd/ [29.05.2019].

---- (2014) [DLE] Diccionario de la lengua española 23. ${ }^{a}$ ed. https://www.rae.es/diccionario-de-la-lengua-espanola/la-23a-edicion-2014 [29.05.2019].

---- (2018) [CORPES] Corpus del Español del Siglo XXI. https://www.rae.es/recursos/ banco-de-datos/corpes-xxi [3.06.2020]. 